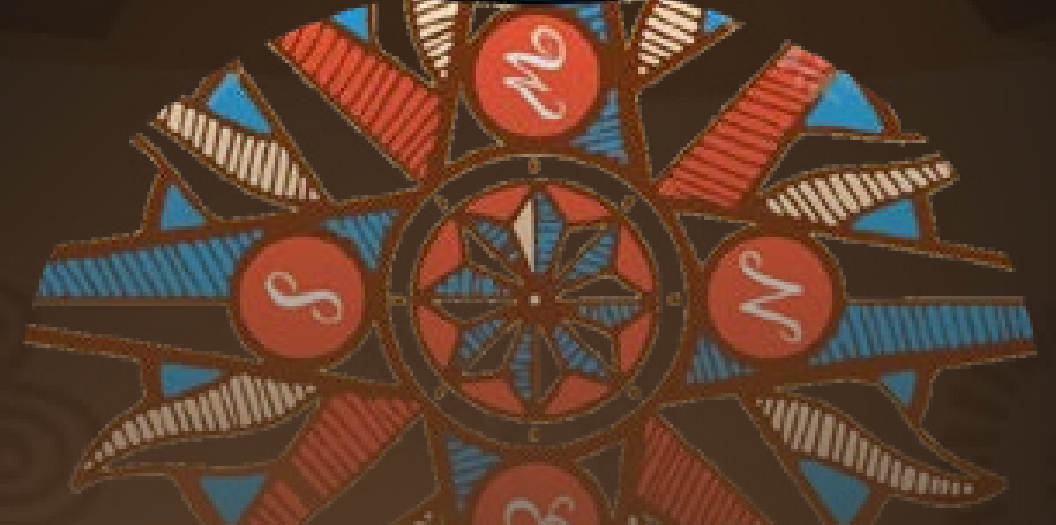




\section{El derribamiento del avión CK123 donde venía E. Hassenfus y el tri- unfo contundente de Nicaragua en la Haya: pasos para consolidar la segunda independencia.}

The downing of the CK123 plane carrying E. Hassenfus and the resounding victory of Nicaragua in the Hague: steps to consolidate the second independence.

Urías W. Ramos Escobar

Docente Investigador

Facultad de Humanidades y Ciencias Jurídicas

UNAN-Managua

ID Orcid https://orcid.org/0000-0002-5110-4497

uramos@unan.edu.ni
Herme J. Ramos Araica

Titular

Instituto Nacional de Cultura

ID Orcid https://orcid.org/0000-0003-0567-7689
Recibido:15- 08-2021

Aceptado: 20-08-2021

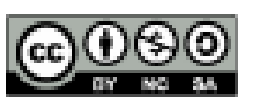

Copyright $\odot 2021$ UNAN-Managua Todos los Derechos Reservados.

\section{Resumen}

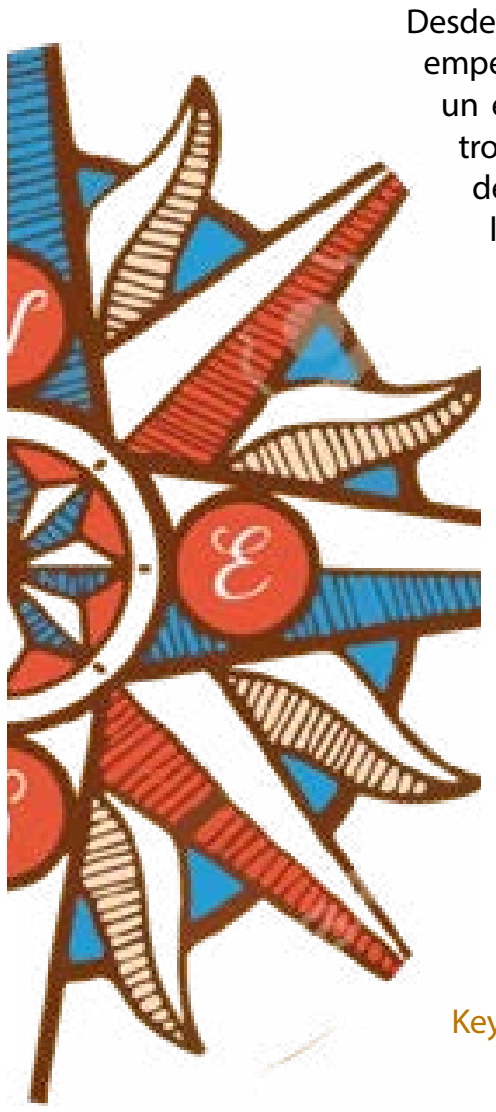

Palabras claves: pueblo, revolucion, soberania

\section{Abstract}

Since the triumph of the RPS on July 19,1979 , the U.S. has been determined to destroy it due to the immediate effect it caused in the region, an example that marked the possibilities for the peoples of Central America and the Caribbean to realize that the Puppet dictatorships of the north were not as unbeatable as we had been told. The U.S. interest was so marked that it distorted, manipulated the population and created the low-intensity war to stifle our revolution by destroying every advance in the economic, social and political field.

Keywords: people, revolution, sovereignty 


\section{Introducción}

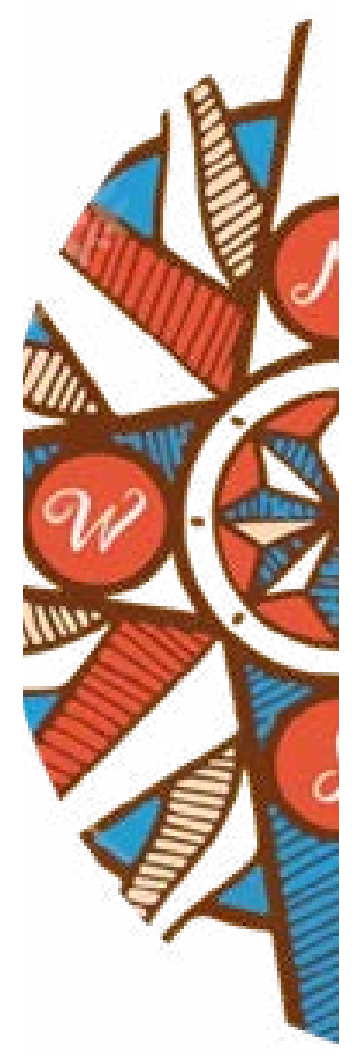

Desde que se produjo el triunfo de la RPS el 19 de Julio de 1979, EE-UU se empeñó en destruirla debido al efecto inmediato que provocó en la región, un ejemplo que marcó las posibilidades para que los pueblos de Centroamérica y del Caribe se dieran cuenta que las dictaduras marionetas del norte, no eran tan imbatibles como se nos había dicho. El interés de los EE-UU fue tan marcado que distorsionó, manipuló a la población y creo la guerra de baja intensidad para ahogar a nuestra revolución destruyendo todo avance en el campo económico, social y político.

Frente a tales amenazas el gobierno revolucionario encabezado por el comandante Daniel Ortega Saavedra aprovechó todos los espacios internacionales para denunciar el ingerencismo e intervencionismo directo e indirecto en nuestro país. En la VIII Cumbre de los No Alineado celebrada en Zimbabwe el 4 de septiembre de 1986 el comandante Daniel Ortega Saavedra en sus discurso inicial reporta que hasta la fecha el costo de la guerra supera los 2 mil 38 millones de dólares, las principales víctimas superan las 1,782 mujeres, 1,112 niños, 14,780 niños huérfanos, 250,000 personas desplazadas de guerra, 22 médicos nacionales e internacionales de Francia, Alemania, 13 enfermera, 198 técnicos, 617 obreros, 42 profesionales, 565 edificios públicos, 33,375 víctimas hasta la fecha.

En este mismo discurso se informa que hasta la fecha se habían realizado 1,500 combates con una baja total de 4,610 muertos, 1000 correspondieron al EPS y 3000 de parte de los mercenarios. Los informes de guerra indican que entre 1980-1987 las localidades que con más enfrentamientos militares y atacadas por la contra fueron: Macuelizo, San Juan de Río Coco, Wiwilí, San José de Bocay, Siuna, Bonanza, litoral Caribe, Jalapa, Waslala, Cuá, Abisinia, Quilalí, Yalí, Limay, Estelí, Matagalpa, Jinotega, Nueva Guinea, Nueva Segovia, Madriz, Río San Juan en todas esta regiones se contaba con la presencia de la Preparatoria participando en las movilizaciones armadas y en las brigadas del trabajo político ideológico.

\section{Desarrollo}

En 1985, la contrarrevolución cambia de táctica organizativa y militar debido que las operaciones militares no habían logrado poner en peligro al gobierno sandinista, la contra pasa oficialmente a llamarse Resistencia Nicaragüense siendo su Directorio Político conformado por Alfonso Robelo, Arturo Cruz, Alfredo César (Siete puñales), no me pregunten por qué y Pedro Joaquín Chamorro. La nueva estrategia utilizada por la resistencia fue la guerra prolongada y de desgaste, ya que no habían logrado producir las bajas necesarias ni acabar con el ejército popular sandinista. 
Por lo anterior, el EPS reorganiza sus fuerzas militares y responde con un nuevo estilo militar, se instauran los Batallones de Ligeros Cazadores con la finalidad localizar, perseguir y golpear a los grupos dispersos que operaban en el territorio nacional. No se puede afirmar que los BLC fueron más certeros que los BLI, pero su principal cualidad fue adaptarse al ritmo de la resistencia nicaragüense por su operatividad, rápidos, bien estructurado y con una formidable capacidad de maniobrar y de adaptación ante cualquier tipo de escenario que le presentara el enemigo.

Los Batallones de Ligeros Cazadores le proporcionaron cuantiosas bajas a la resistencia nicaragüense, por otro lado, le crearon la idea colectiva de terror y de zozobra, cuando se percataba de su presencia en el teatro de operaciones militares. Este tipo de fuerza irregular combinado con los BLI garantizó la derrota total y absoluta de la resistencia nicaragüense, lo digo con propiedad y conocimiento militar. Cuando el comandante Daniel Ortega Saavedra se presentó en la mesa del diálogo con la resistencia nicaragüenses fue absoluto y categórico en afirmar que los mayores logros de la revolución habían sido los triunfos en Corte Internacional de Justicia, las relaciones internacionales y la derrota militar de la resistencia nicaragüense, pero que el talón de Aquiles era la economía. (Memorias, 1979-1990. p.40)

Toda la década de los años ochenta se caracterizó por presentar una situación política militar crítica, por efecto de la guerra impuesta por el imperialismo norteamericano y como resultado del descontento de un sector de la población que se opuso al proceso revolucionario. Esta coyuntura fue aprovechada por los EE-UU, dirigiendo todos sus esfuerzos en acabar con el proceso revolucionario, de ahí, que sus dos ejes fueron manifestarse primero de forma encubierta, luego de forma abierta con el apoyo de la contrarrevolución, brindándole asesoría y financiamiento.

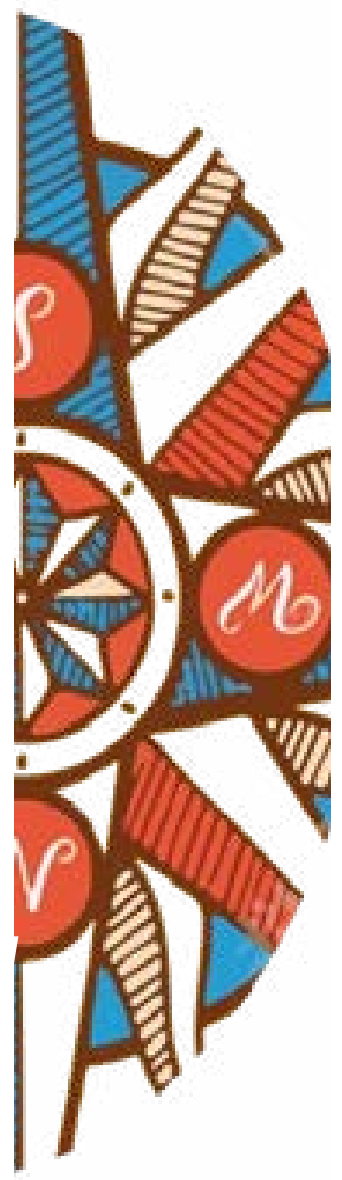




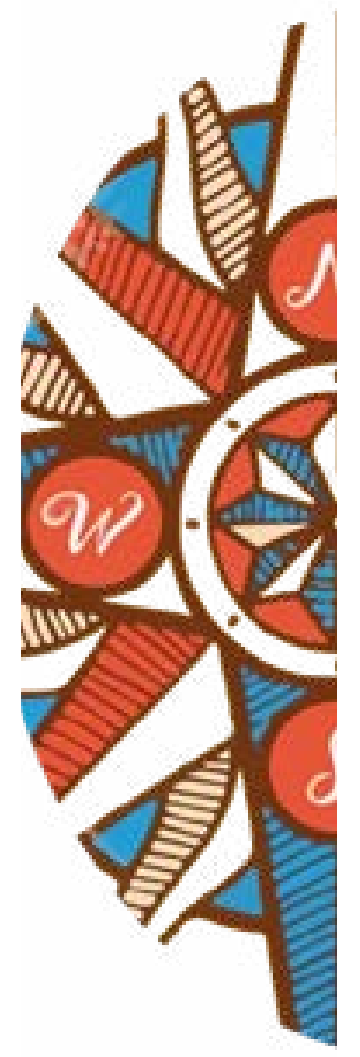

Sobre la participación de los Preparatorianos en este período es importante el testimonio del actual Director de la Prepa José del Carmen Miranda (2010), cuando señala que: En la década de los 80 la Preparatoria fue un bastión político militar del FSLN, la inmensa mayoría de los estudiantes estaban integrados a las asambleas de base de la JS19 de Julio, Comité de Base Sandinista del FSLN, Milicias, BLI, SMP, brigadas: productivas, cortes de café, algodón y hasta trigo, en el campo ecológicos, saneamiento ambiental y brigadas ecológica, las autoridades universitarias tenían que detener a los estudiantes cada vez que se movilizaba un contingente (pag.2)

Uno de los actos heroicos ocurrido el 5 de octubre de 1986 y que aun está presente en la memoria colectiva del pueblo de Nicaragua, lo constituyó el derribamiento del avión CK123, Mini-Hércules cuando tres valientes jóvenes, dos de ellos fueron parte de la Preparatoria de Obreros y Campesinos. Estos valientes muchachos realizaron una de las hazañas más significativas para la historia de este país el mayor acto de heroísmo en toda la década de los años 80, me refiero al joven José Fernando Canales Alemán, Byron Antonio Montiel Salas y Raúl Acevedo, se convirtieron en los responsables de derribamiento del avión CK-123, donde venía el norteamericano E. Hassenfus en el caso de Raúl Acevedo fue quien captura de Eugene Hassenfus.

De acuerdo a los registros y fuentes históricas de la época, ese día se encontraba acampando la compañía del batallón Ligeros Cazadores con el nombre "Laureano Mairena", cuando se dio la orden de buscar la mejor posición para proceder con el disparo certero. El compañero José Fernando Canales Alemán apunta con la flecha el objetivo militar y el compañero Byron Montiel Salas enciende la fuente, se realiza el disparo en dirección a la fuente calórica del motor, se produce el impacto y el avión se desploma. José Fernando Canales Alemán (2018), autor del derribamiento del avión CK-123 al ser entrevistado comentó que:

Eran las 12: 45 de la tarde nos encontrábamos preparando un mono sancochado que se miraba sabroso para almorzar. Teníamos 19 días de estar operando, bueno en el lenguaje militar de estar en misión, de un total de 2 meses que teníamos que estar enmontañado. De repente el escolta del Jefe de Plana Mayor nos grita que se escucha un avión, inmediatamente nos ponemos ojo al Cristo, en ese momento para nada nos acordamos de la comida, preparamos la flecha C2M, escuchamos la voz de mando del jefe que nos dijo- ¡Flecheros prepárense, un blanco se aproxima (avión), entre los nervios y las ganas de cumplir la misión no sabía qué hacer, así que le pedí al compañero Byron Montiel Salas que me encienda la fuente. En este instante calculé que el blanco estaba a 5000 mil metros de distancia, esperé su aproximación y exactamente a los 3000 metros lo colimé, encendí el primer tiempo lo localizó, se mete en una nube y pierdo temporalmente la ubicación del blanco. Al salir de la nube se vuelve a encender la fuente, jalo el gatillo, observamos que el disparo impacta en cinco minutos el ala derecha e inmediatamente se desploma cayendo a pique. 
Durante la picada que hizo el avión se observa que un bulto se desprende de la puerta principal, notándose que era el paracaídas que había utilizado E. Hassenfus más tarde capturado por el soldado Raúl Acevedo, entregado a las autoridades militares para luego llevarlos a los TPA (Tribunales Populares Anti somocista).

Según el Diario Barricada del domingo 2 de noviembre de 1986 destaca que: El soldado Byron Montiel Salas respondió de la misma forma con que lo hizo José Fernando Canales Alemán ante el caso de E. Hassenfus, señalando que a las 4 de la tarde del día 6 de octubre él y su compañero, los mandos de la COI (Compañía), les encomendaron cuidar a Hassenfus, mientras cumplimos la orden, nos pidió agua por medio de señas y procedimos a dárselas y le proporcionamos comida (p.6). También ante los TPA, se presentaron otros soldados uno de ellos fue Ángel de Jesús Tenorio Galeano conocido en la Prepa como (el Gato), Feliciano Orozco y Freddy Noel Díaz García.

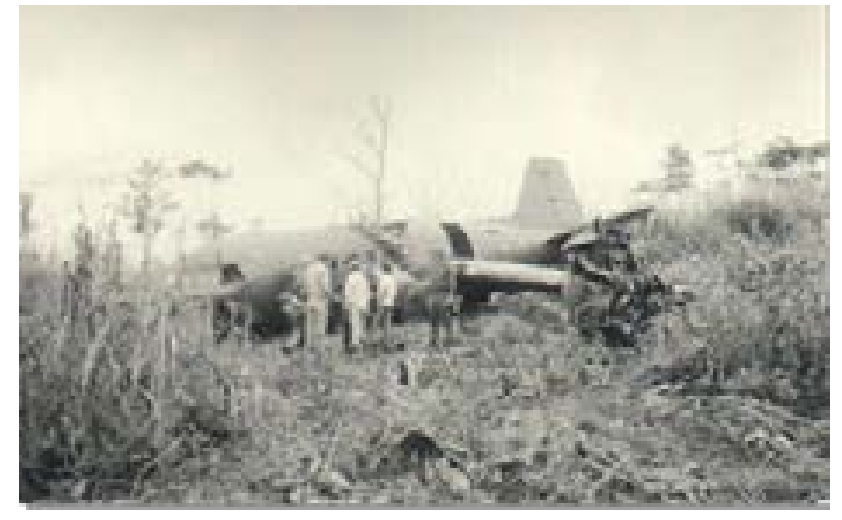

llustacion 2. Derribamiento del avión CK-123, de parte de los egresados del Proyecto Político Ideológico de la Facultad Preparatoria el 5 de octubre de 1986.

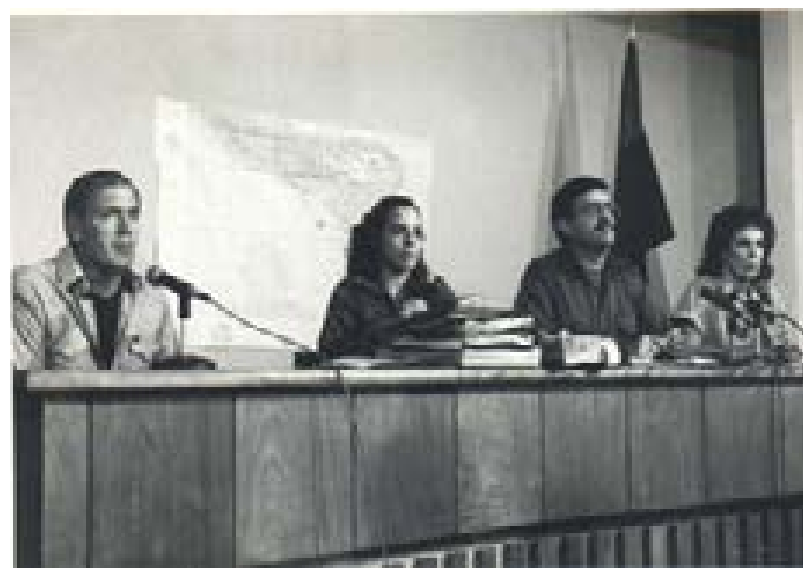

Ilustacion 3. Imagen de Byron Montiel Salas y Fernando Canales Alemán autores del derribamiento del avión CK-123, donde se muestra al norteamericano E. Hassenfus presentado ante los Tribunales nicaragüense.

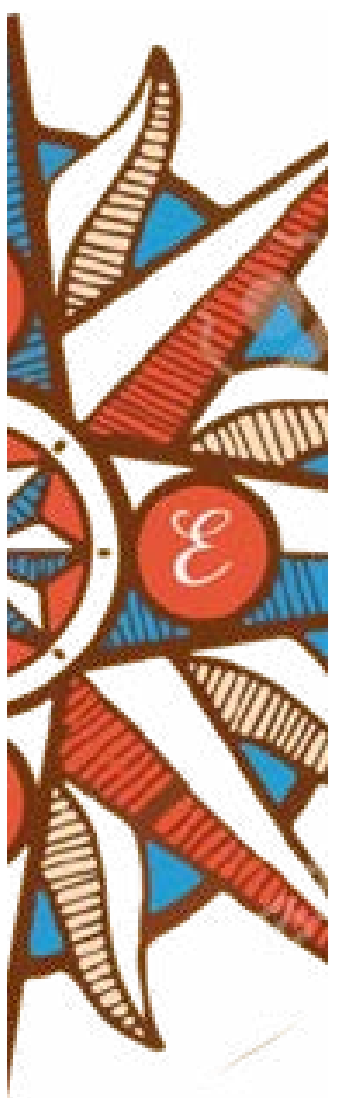




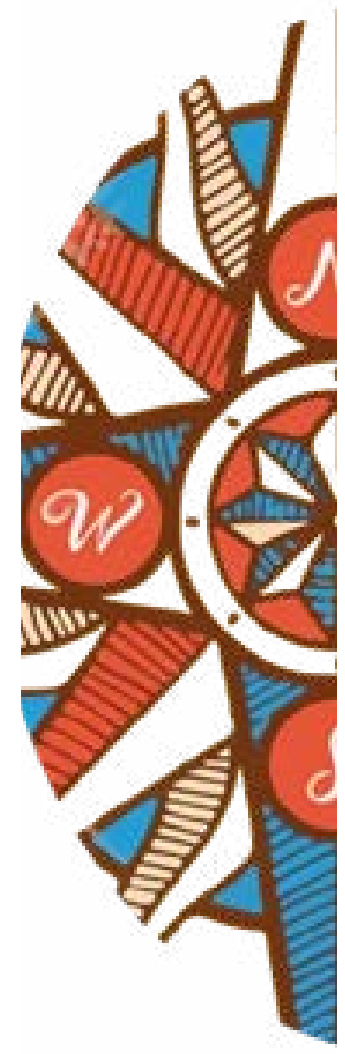

En 1986 Eugenio Hassenfus fue llevado a los Tribunales Populares Anti somocista (TPA) con la finalidad de responder por daños y agresión a nuestro país. Barricada (1986), informa que Canales relató cómo los miembros de su compañía llegaron hasta el avión en llamas, encontrándose con los pertrechos militares y los cadáveres de dos norteamericanos y un latino la mañana del 7 de octubre de 1986. Continúa narrando que arribaron al lugar en que había caído el avión y que el reo le fue entregado a los altos mando de la V Región Militar, encabezado por el Teniente Coronel Roberto Calderón.

José Fernando Canales Alemán, Byron Montiel Salas y Ángel de Jesús Tenorio Galeano fueron estimulados por la Dirección Nacional del FSLN para ingresar al Proyecto Político Educativo de la Facultad Preparatoria habitando en la casa N. 133 donde compartimos muchas experiencias propias de nuestra juventud, coincidimos en que todos los becados internos habíamos sido parte del EPS, como soldados, clases y oficiales y desmovilizados del SMP. Esta condición marcó una relación que ha durado toda una vida y en los momentos fugaces en que nos volvemos a rencontrar, nos seguimos viendo como hermanos de lucha, con una marcada convicción revolucionaria producto de nuestra formación en el Proyecto Político e Ideológico de la Facultad Preparatoria.

El caso E. Hassenfus vino a confirmar la denuncia que se venía haciendo en contra de la intervención directa en los asuntos internos en nuestro país, la Dirección Nacional conjunta, dirigida por el comandante Guerrillero y presidente de la república de Nicaragua, Daniel Ortega Saavedra venía en reiteradas ocasiones denunciando los graves daños que la política exterior del gobierno de los EEUU había impuesto durante la década de los años 80 . La captura del norteamericano confirmó la presencia e involucramiento de asesores, marines y funcionarios del país del norte en la guerra contra Nicaragua y esta fue la prueba más contundente para que la HAYA definitivamente tomara la decisión de condenar al amo imperial, como decimos en el buen nicaragüense nos cayó del cielo la prueba que necesitábamos para terminar de condenar a los EE-UU.

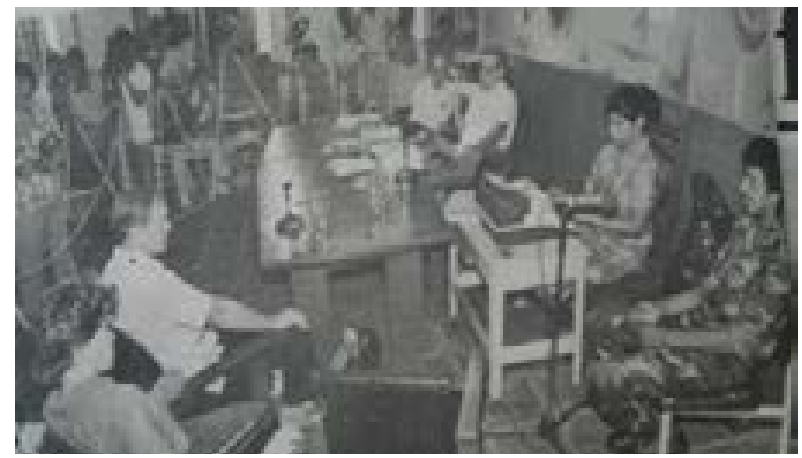

Ilustacion 4. Byron Montiel Salas declarando ante E. Hassenfus a solicitud del presidente de los TPA, Doctor Reynaldo Monterrey. Fuente: Barricada (1986) 
Producto de la captura de E. Hassenfus Nicaragua, logra demostrar en la Corte Internacional lo que había estado a la vista de la opinión internacional, la presencia e interés de los agentes de la CIA por derrotar al gobierno, sin importar los cuantiosos daños humanos y materiales causados a nuestro país. Gracias a la acción heroica realizada por Byron Montiel Salas, Fernando Canales Alemán y Raúl, el máximo tribunal de justicia condena al país del norte por daños de lesa humanidad.

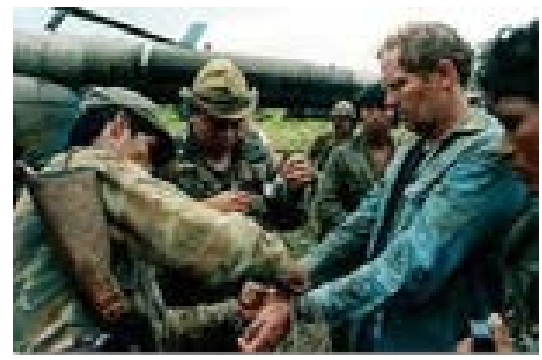

Ilustacion 4. Entrega del norteamericano E. Hassenfus a las autoridades militares de la Zona Especial III, al fondo Fernando Canales Alemán y derecha asomando la cara otro héroe de la Prepa, Ángel Tenorio Galeano conocido en los frentes de guerra como (EI Gato).

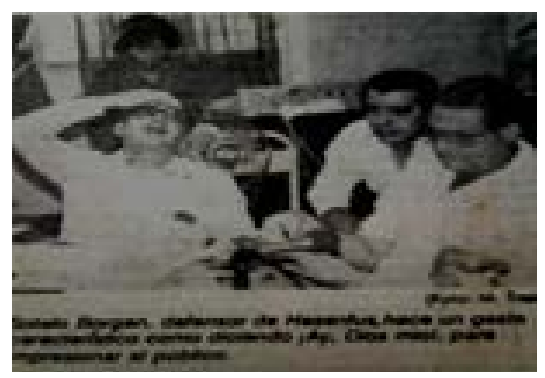

llustacion 5.Defensor del mercenario Norteamericano E. Hassenfus frente a los TPA quien no pudo sostener la defensa del reo frente a los héroes Fernando Canales Alemán, Byron Montiel Salas y Raúl Acevedo, Fuente: Barricada (1986), Sotelo Borgen

La Corte Internacional de Justicia Obliga a EE.UU el pago como indemnización por los daños causados al Estado de Nicaragua de 17,000 mil millones de dólares, sentencia que nunca honró por su naturaleza agresiva e imperial, ceder ante un pequeño país significaría un ejemplo a seguir por otros Estados, basta recordar que la diplomacia revolucionaria fue muy efectiva durante los años 80 , y estuvo enmarcada en la lucha por la defensa de la soberanía Nacional, es importante recordar que la presidenta Doña Violeta Barrios de Chamorro como un acto de buena vecindad y de buenas relaciones anula la sentencia dejando en la indefensión al país. En los años 90, los EE-UU comenzaron a vestirse con piel de oveja pero con diente de lobo, producto de su política de defensa de los Derechos Humanos que ellos mismos han venido violentando en el mundo con su política agresiva.

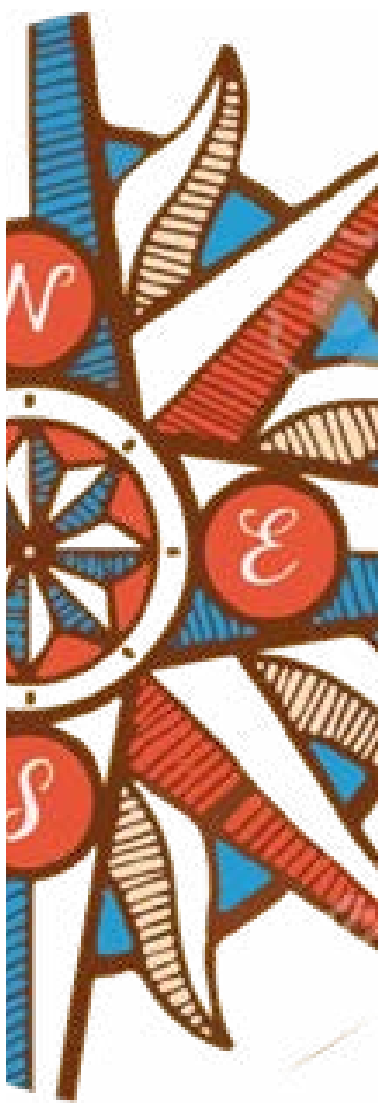

Basta recordar que desde el punto de vista económico este país pudo haber honrado esta deuda pero desde el punto de vista moral significó un ejemplo dado que fue un país excepcional y pequeño quien lo vence en los tribunales superiores. Así que el gobierno de Doña Violeta de Chamorro tuvo que anular la sentencia para evitar que los recursos prometidos se hicieran una realidad y claro esta que bajo tal chantaje se produjo la entrada de recursos líquidos que quedaron en las manos de ¡Alí Baba y los 40 ladrones; 


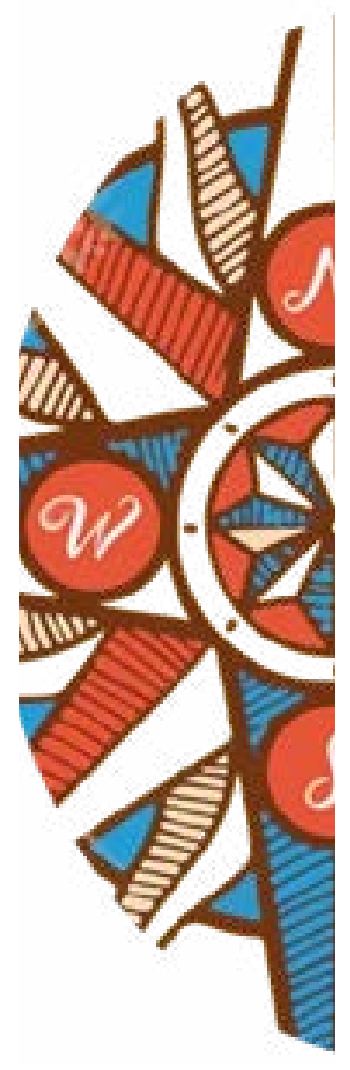

Independientemente de la actitud negativa de no reconocer la sentencia del máximo Tribunal de Justicia el gobierno contó con el apoyo internacional del cual fue objeto el pueblo nicaragüense y su revolución, sumado a esto la gran cantidad de brigadas internacionales que visitaron nuestro país que se integraron sobre todas las cosas en todos los procesos de desarrollo económico y social. Lo anterior, reafirma los resultados positivos que tuvo la revolución en los años 80 en materia internacional y con respecto a los reclamos territoriales contra los países vecinos.

No puedo dejar de mencionar al veterano de guerra Bryan Wilson quien frente a la escalada agresiva norteamericana sobre Nicaragua se puso al frente de un contingente para detener la caravana de los trenes que traficaba con armas destino a la contrarrevolución perdiendo su pierna, hago mención de este héroe de guerra debido que fue objeto de discusión y estudio en la Preparatoria y en los cursos de preparación política de la JS19J.

La gesta heroica de los valientes jóvenes de la Facultad Preparatoria marcó el fundamento ideológico de la lucha de Sandino, el antiimperialismo quedó reafirmado ,basta recordar la frase del general Augusto César Sandino cuando se referiría a la presencia norteamericana en nuestro país ¡Más de un batallón de los vuestros, invasor rubio, habrá mordido el polvo de mis agrestes montañasi Una vez más queda demostrado que la EsEs- 11 ustac Cuela Preparatoria fue un bastión de la re olución y semillero de los futuros cuadros del FSLN materializándose esta idea durante la segunda revolución muchos compañeros están en los diferentes cargos de las instituciones del Estado.

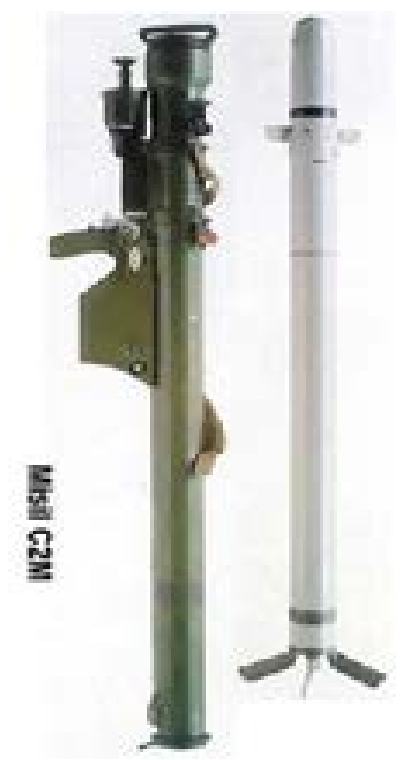

Ilustracion 6. Fuente: Imagen brindada por José Fernando Canales Alemán autor del derribamiento del avión CK-123 donde venía mercenario norteamericano E. Hassenfus con el misil C2M, conocidos por los cachorros como la aguja.

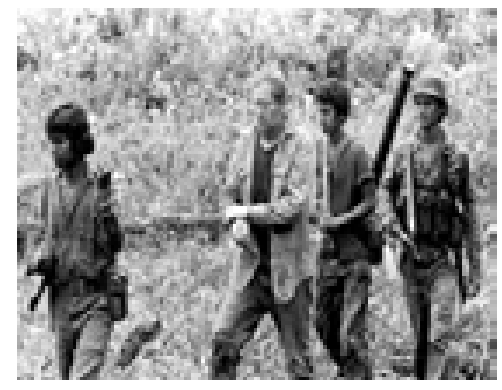
de 1986 producto del derribamiento del avión CK-123. 


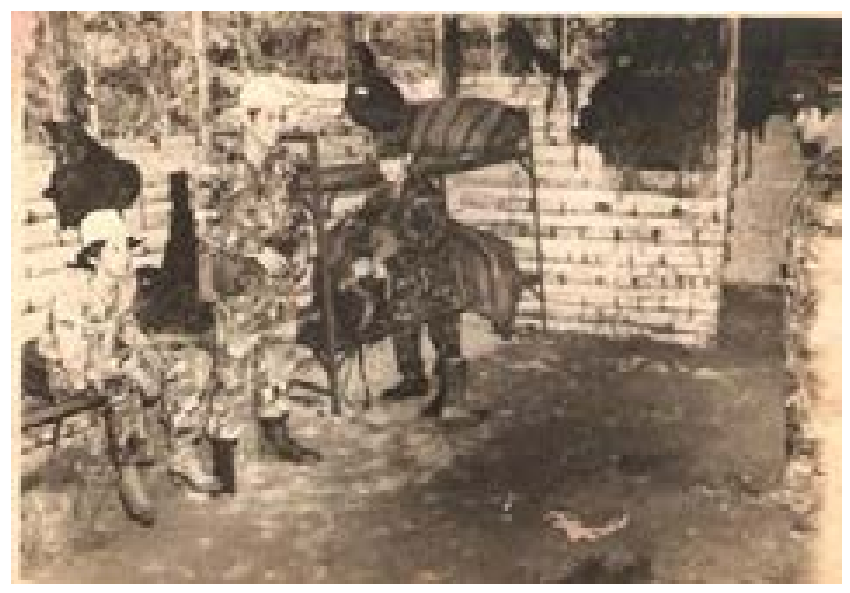

llustracion 8. De pie en la parte izquierda con la mano en la funda de su revólver

Napoleón Reyes Valle posa con el uniforme militar de Guarda fronteras en un lugar de Nicaragua

La Preparatoria como Proyecto Político e Ideológico siempre estuvo inmersa en los conflictos armados, estaba en todos los frentes de guerra, en los años 80 tenía la tarea de levantar la producción del rojito en las zonas de combate así lo hizo, estaba presente en los sitios donde operaba la contrarrevolución. Hay que destacar que la mayoría de los estudiantes tenían experiencia militar muchos fueron parte del EPS formando las distintas fuerzas armadas tales como: desmovilizados del SMP EPS, MINT, PUFE, COPETE, TPA, TPU, MPS, SMP, SMP de mujeres conocidas como “Las Cachorras.", Reserva, JS19J, CODE, CP)

El cumplimiento de las tareas de la revolución en los años 80 y particularmente en la Escuela Preparatoria no tenía ninguna compensación monetaria, la mayor recompensa fue el deber cumplido, por tal motivo, para un estudiante de la época lo más sagrado fue la defensa de la revolución y las reivindicaciones. Para nutrirnos ideológicamente teníamos que leer profundamente textos de orientación socialista como capitalista, de ahí derivaba nuestro sustento político, las escuela de cuadros estaban a la orden del día, ninguna compensación monetaria superaba nuestra mística revolucionaria y a pesar de nuestras necesidades este principio fue alimentado con el deber cumplido. La JS19J tenía diferentes estímulos que debíamos de ganarnos según el grado de cumplimiento de las tareas políticas y militares, parafraseando a mi maestro y mentor Miguel De Castilla Urbina "la juventud de los años 80 , estuvo fundida con hierro candente"

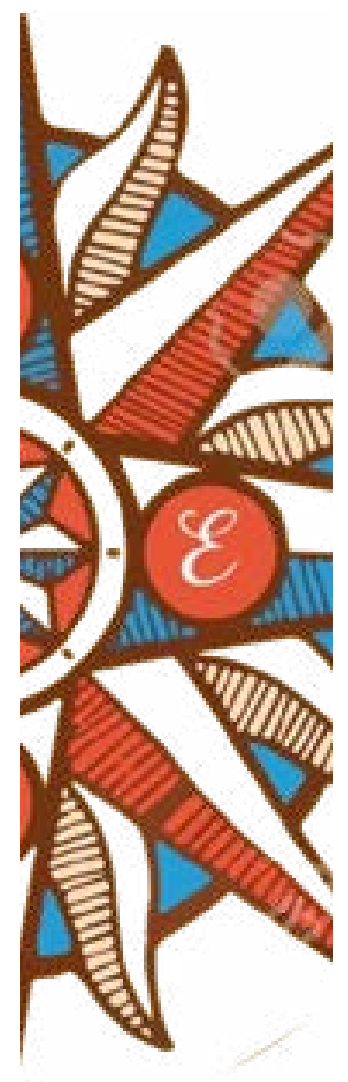




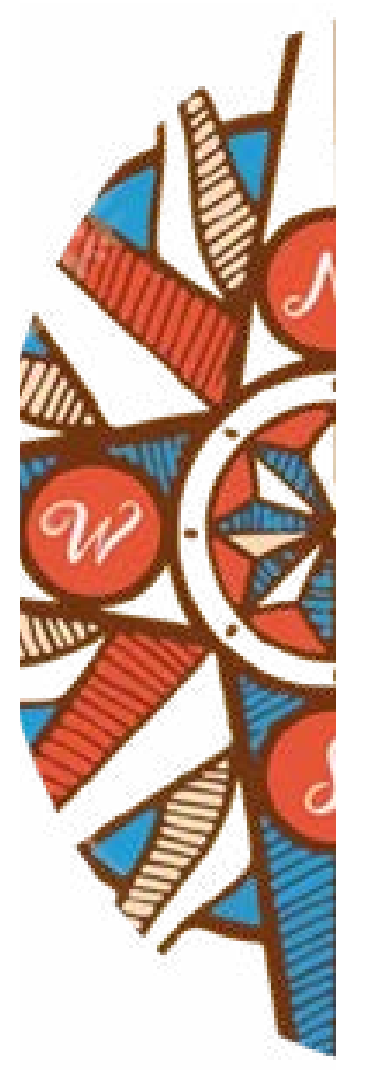

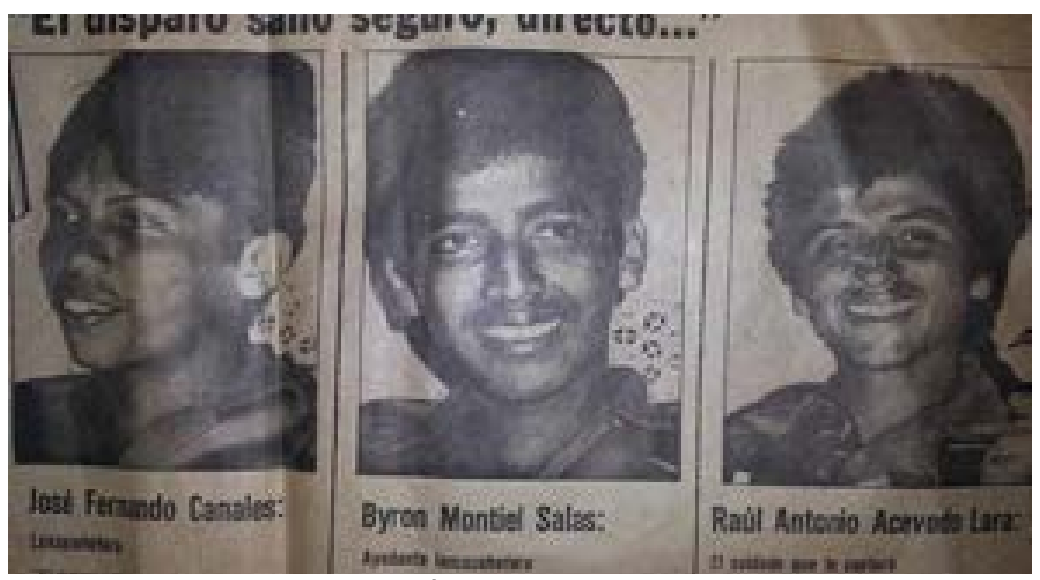

llustacion 9. Barricada (1986). Los tres héroes de la patria brindando declaraciones sobre el derribamiento del avión CK-123 y la captura de E. Hassenfus dos de ellos estudiantes de la Facultad

Preparatoria

Un hecho reciente fue mi designación en el año 2013 para ser parte de la UNAN-Managua en participar en el Departamento de Río San Juan, San Carlos, como docente en el Proyecto "Río San Juan", proyecto del CNU Consejo Nacional de Universidades atendido por la UNAN- Managua, y la UNAN- León. El objetivo de este proyecto fue la formación de profesionales con el fin de potenciar la región con cuadros calificados en todas las áreas como Turismo, educación, agronomía, salud y contabilidad. Aprovechando mi estancia me dediqué a contactar muchos compañeros egresados de la Preparatoria para establecer los preparativos de este libro y conformarnos en un movimiento de "Cumplidores por la paz" como desmovilizados de las armas. Entre los asistentes de la Prepa estaba Cristóbal Salas, Fernando Canales Alemán, Byron Montiel Salas, Ángel Tenorio Galeano y su servidor. En la reunión se acordó formar el Movimiento de Cumplidores por la Paz en todo el departamento, quedando la propuesta de Byron Montiel Salas como su coordinador.

Por otro lado, sostuvimos varias reuniones con los compañeros desmovilizados del SMP del departamento de Río San Juan, de formar una sola organización capaz de enfrentar las demandas sociales de muchos excombatientes que están en condiciones críticas y que ameritan nuestra ayuda y solidaridad, eneste mismo encuentro, se trató la temática de cómo aprovechar los servicios de muchos colegas médicos y profesionales para que por medio de ASOPREPA lográramos brindarle cierta atención a los compañeros. 


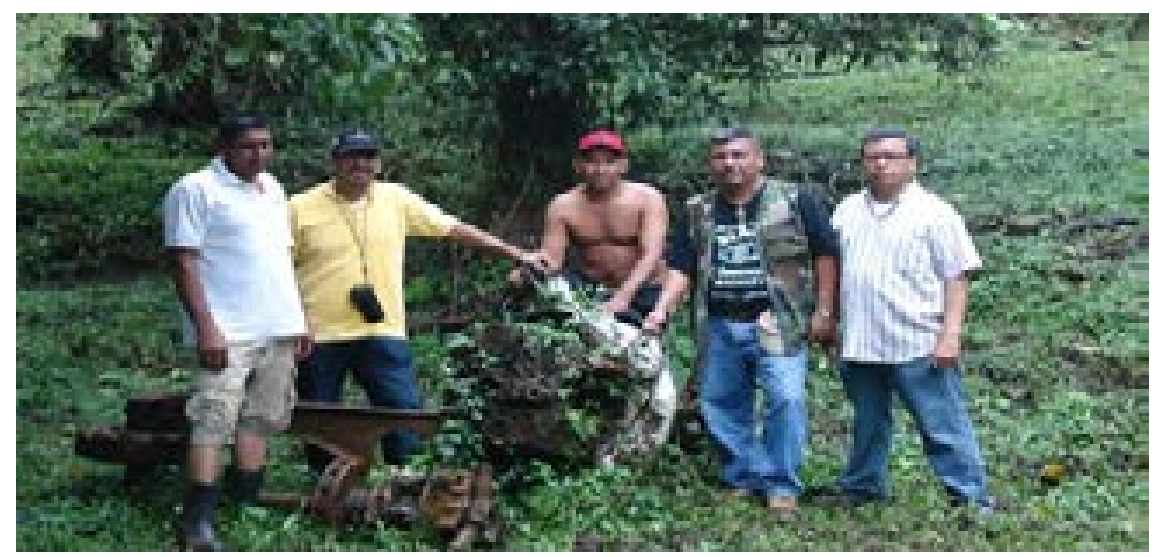

Ilustacion 10. Archivos del autor. José Fernando Canales Alemán y Byron Antonio Montiel Salas con el apoyo del Ejército Nacional visitando en la los restos del avión CK-123 derribado el 5 de octubre de 1986 en la zona

Mi estadía en San Carlos, Río San Juan, me permitió organizarnos como grupo de desmovilizado y ex egresados de la Prepa, sin desatender la idea de que estaba de paso cumpliendo con una tarea específica, impartir la cátedra de Geografía e Historia a los alumnos de la universidad de San Carlos adscrita a la UNAN, Managua. En el encuentro se pensó en la propagación de la idea de crear un museo en el malecón de San Carlos, con los restos del avión derribado por José Fernando Canales y Byron Montiel Salas, los compañeros me comentaron en esta oportunidad, que en 1997, un funcionario de gobierno dio la orden para que los restos se vendieran como chatarra y durante semana estuvieron en el puerto bajo la espera de ser transportado a la capital y vendido al hermano pueblo de El Salvador.

En vista de esta atroz decisión de borrar la historia y quitarle mérito a la gesta heroica de los compañeros, José Fernando Canales Alemán, Byron Montiel Salas, acompañados por un selecto grupo del Ejército Nacional, se visitó el sitio para constar in situ, los restos del avión y comprobar lo que había quedado. Los compañeros determinaron que a pesar de la mala decisión de autorizar la venta de los restos, aún existían algunas partes que podían ser objetos de un museo.

Observaron que las alas del aeroplano estaban siendo utilizadas para la crianza de palomas "De Castilla", quedando en evidencia la creatividad e ingenio del nicaragüense que octubre de 1986. siempre saca de las desgracias situaciones muy agradables y chistosas, así somos y hemos sido, esto es lo que nos hace ser nicaragüense, pero también pinoleros. La creación del museo en el malecón de San Carlos es un tema que ha estado pendiente por cuanto no se le ha podido explicar profundamente la importancia del mismo, al compañero Alcalde de San Carlos, con la realización de este centro se potenciaría la historia, la identidad y el turismo local, basta recordar que San Carlos es un bastión del turismo nacional e internacional.

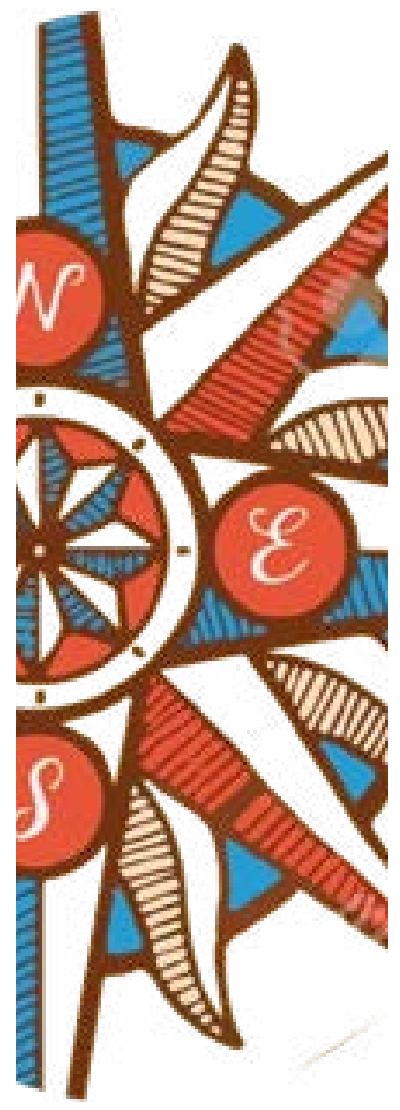




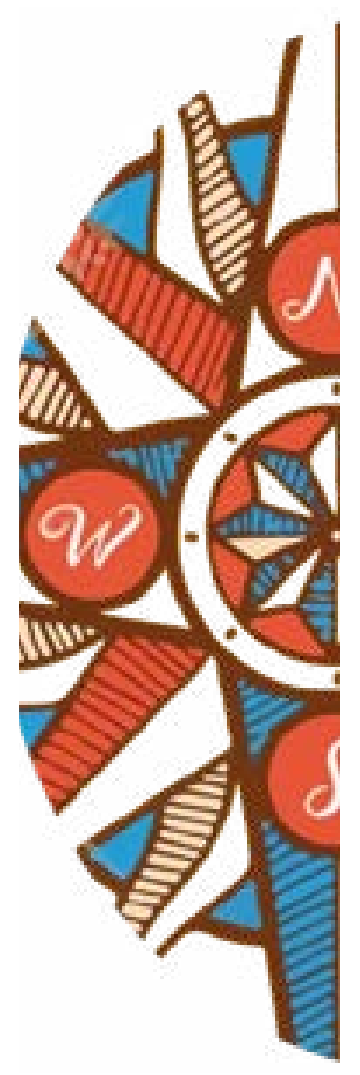

Un aspecto importante en los años 80 fue el papel que jugó la Juventud Sandinista 19 de Julio, como heredera y defensora de las conquistas de la revolución popular sandinista, contaba con diferentes grados de estímulos para otorgarlos en asamblea extraordinarias. El primero fue el broche de guerrillero de la alfabetización lo recibía todo aquel miembro de la JS19J en la vía civil y militar que era muy persistente con la tareas juveniles, seguido de otro estímulo llamado Joven Sandinista donde aparecía un soldado del general Sandino haciendo el famoso corte de chaleco con un machete, pero lo más difícil en esta organización fue alcanzar el grado de Juventud Sandinista Vanguardia y para nosotros los Prepas sin modestia alguna, lo obteníamos con mucha rapidez por nuestra combatividad y disposición en las tareas de la revolución.

Además de estos estímulos existieron otros reconocimientos en forma de diplomas que muchos de los miembros de la Prepa atesoramos y hemos guardado para poder recordar para toda la vida que fuimos parte de un proceso revolucionario y de una época histórica que marcó profundamente la juventud nicaragüense. Los años ochentas, estuvieron dedicados para la defensa, estudio y producción, la JS19J siempre valoró el trabajo, la abnegación y el esfuerzo personal y colectivo, todo esto se vio reflejado en la cantidad de estímulos que pudo haber recibido un Prepa. Cada tarea cumplida en los años 80 , terminaba con una asamblea cuyos componentes principales marcaban la crítica y la autocrítica de lo que se hizo, se valoraba el trabajo organizativo y la efectividad del mismo con la entrega de distintos estímulos materiales y morales, esto te impulsaba y te llenaba de regocijo, de un profundo valor para continuar en la senda de la defensa de los logros de la revolución.

La segunda etapa de la revolución 2007 a la actualidad, presenta las mismas características del trabajo político organizativo, pero no se ha podido estimular de forma individual y colectiva el trabajo realizado por la militancia de base. Hemos abandonado esta cualidad revolucionaria y la hemos sustituido por otras. El trabajo evaluativo le dio sentido a la militancia en los años 80 , logrando empoderar los sectores marginados que solo la revolución pudo rescatar y que en la actualidad producto de las oportunidades que brindó la revolución se han convertido en agentes de cambio de su propia historia.

En la actualidad el militante está lleno de disposición y trabajo, pone en práctica el bien común que nos es más que la satisfacción de ver la superación de los más desprotegido y como la revolución restituye los derechos. Pero el militante se olvida de sí mismo cuando se ve inmerso en esta noble tarea, en lo personal, pienso que debemos darle valor y sentido al trabajo que realiza cada compañero siendo parte de una política de estímulos materiales y morales, por qué no?. 
En la Facultad Preparatoria no solo se trabajaba con la sensibilización de la sociedad nicaragüense también hizo suyo el llamado de formar parte de las fuerzas armadas en todas sus dimensiones, en la medida que se creaban los contingentes en los barrios, estos fueron acompañados por grupos de estudiantes. Atendíamos sin vacilar los llamados que hacían los zonales de reclutamiento que por lo general solo tenían cabida para los jóvenes de los barrios. En la Facultad por el contrario, se formaron los contingentes voluntarios al SMP el primero de tantos, se estableció en 1986, en este grupo estaba Francisco José Torres quien regresó en 1988 integrándose en II Nivel con el grupo que iniciamos en 1987.

Fueron miembros de esta movilización Francisco José Torres, César Brenes, Wilfredo Manzanares (Nueva Guinea), Manuel Bermúdez, lograron formar parte del BIR-15-15, (Batallón de Infantería de Reserva) en 1983, conocidos como los batallones de reservas que junto con las MPS (Milicias Populares Sandinista) que sin lugar a dudas fue la antesala del SMP. Los estudiantes regresaron en 1984 y se integraron directamente en los cursos especiales en I Nivel, luego de marzo - agosto de 1985, se movilizaron nuevamente hacia Quibuto, en este mismo año como ya se ha mencionado forman el contingente voluntario del SMP, integrándose en II Nivel en 1988.

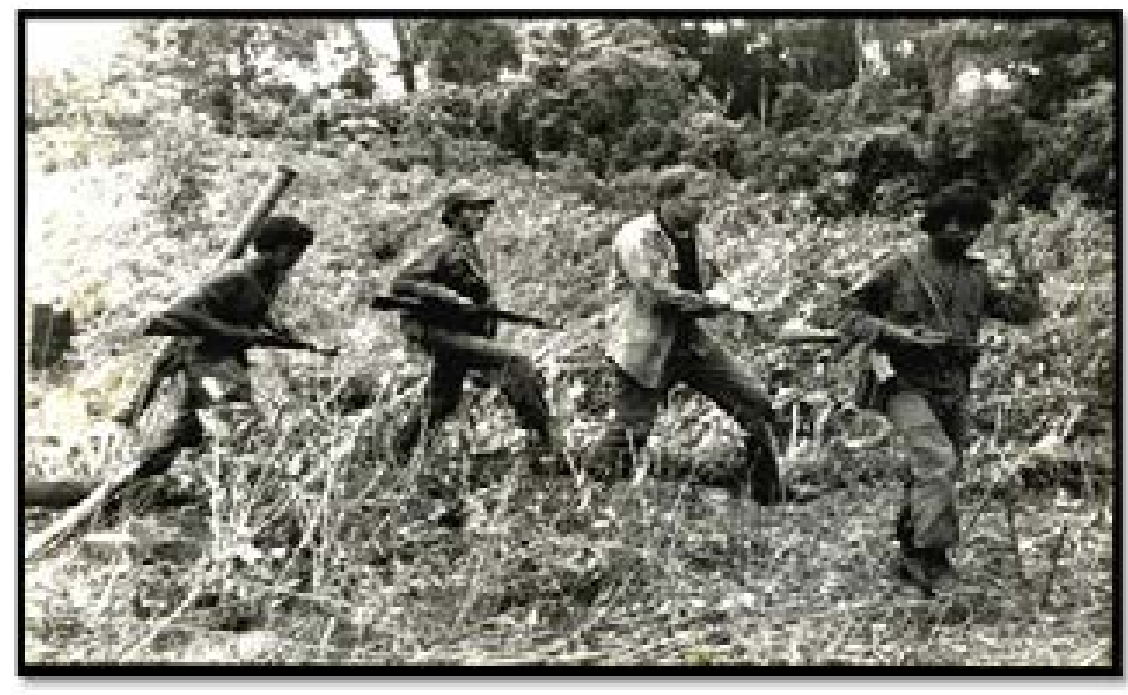

llustacion 11. Imagen cortesía José Fernando Canales Alemán. Traslado del estadounidense E. Hassenfus del Tule, Río San Juan hacia los TPA (Tribunales Populares Anti somocistas) quien fue capturado el 6 de octubre de 1986, en la comarca EI Fajardo después del derribamiento del avión CK-123. En la imagen se observan los tres héroes José Fernando Canales Alemán, Byron Montiel Salas egresados de la Preparatoria y Raúl Acevedo.

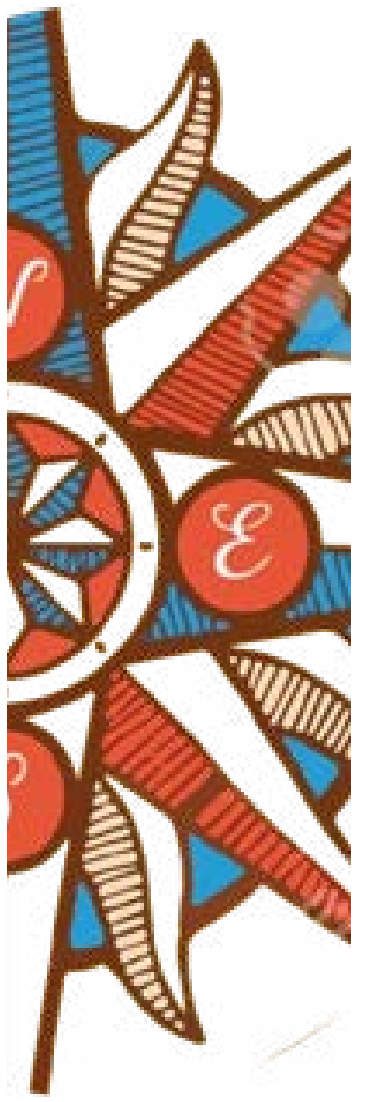




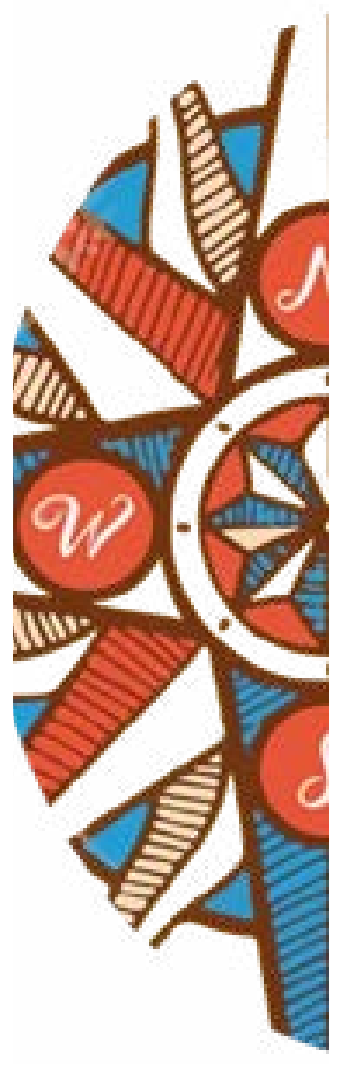

\section{Conclusión}

Después de 35 años de haberse producido la gesta heroica que marcó un paradigma en la historia al ser condenado los EE-UU, este 5 de octubre marca el compromiso militante de quienes hicieron posible esta acción nos referimos a los héroes Byron Montiel Salas y José Fernando Canales Alemán con quienes he cultivado una amistad que nace desde las entrañas del sandinismo como militantes y ex cachorros del SMP, y que jamás hemos renunciado a nuestros principios revolucionarios y nos mantenemos incólumes e inmaculados en los ideales de la revolución defendiendo con ahínco las conquista y respaldando al FSLN, cuyo líder indiscutible ha sido y será el comandante Daniel. En palabras de uno de los protagonistas de tal acto heroico nos referimos a Byron Montiel Salas nos refiere que después de 35 años del derribamiento del avión CK-123 :

Al hablar sobre esa gran gesta histórica, que significó mucho en los años 80 donde se le demostró al mundo con mucha evidencia la injerencia directa de EE-UU, hacia Nicaragua, desde ahí, estamos claro que el enemigo sigue siendo el mismo. Cuando nosotros hoy en día miramos y escuchamos sobre el caso Hassenfus nos llena de mucha fortaleza, valor y nos comprometemos mas con este modelo revolucionario que dirige el comandante Daniel. Después de 35 años de esta gesta nuestro ideal sigue siendo el mismo que nos impregnaron los héroes y mártires, nuestros hermanos caído en el SMP. Seguir firmes con nuestros ideales revolucionarios viendo como el país se transforma cuyo mayor benefactor ha sido el pueblo humilde y trabajador, una obra dantesca que ha venido impulsando nuestro gobierno, sacando adelante al país con crecimiento y justicia social, amor al prójimo que no es más que el mismo pueblo, algo que jamás tendrán el minúsculo grupo de seudo fascista y ultraderechistas que se dedicaron a crear muerte, dolor y luto en nuestro pueblo destruyendo los bienes elementales que había venido impulsando la revolución.

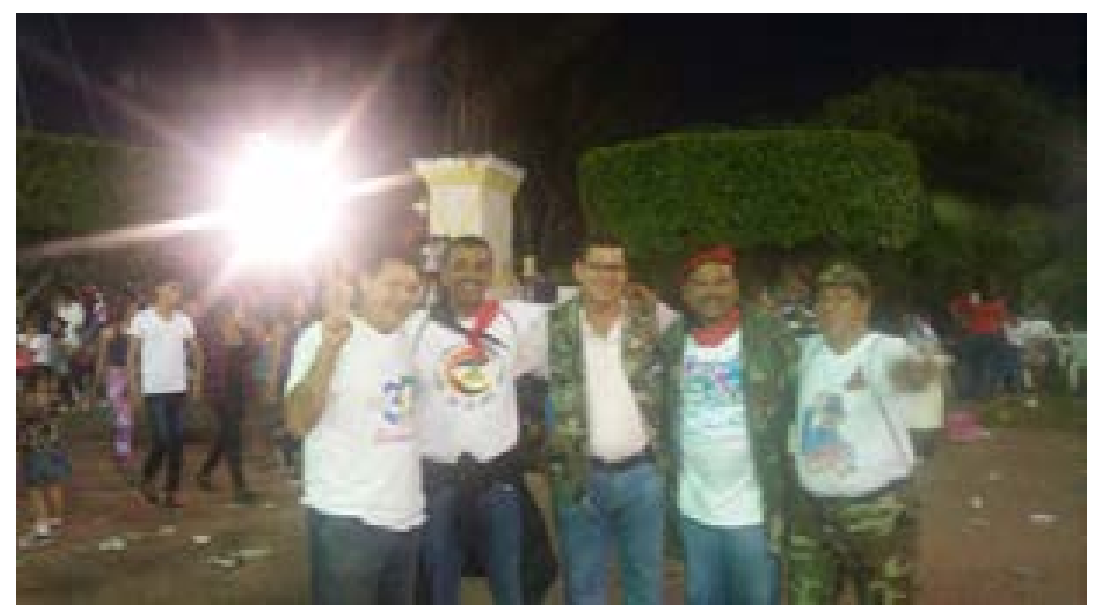

Ilustacion 12. Celebracion año con año de la RPS. De izquierda a derecha los ex cachorros William Antonio Aragón Oporta, Byron Montiel Salas ( Hassenfus), su servidor Urías W. Ramos Escobar, José Fernando Canales ( Hassenfus) y Santos Flores Centeno. Fuente propia 
La Revolución Popular Sandinista vino a consolidar la identidad, la pertenencia y la independencia externa e interna contra cualquier forma de ingerencia de los agentes externos hacia nuestras decisiones como estado soberano. En el acto del derribamiento del avión CK123 donde venía Eugene Hasenfus, fue el punto que marco la intromisión directa de los Estados Unidos hacia nuestro país; pero también, fue la oportunidad que tuvimos como pueblo y revolución para consolidar definitivamente nuestra independencia que venía construyendo desde 1821 a la actualidad.

Como dijo el presidente comandante Daniel Ortega el día 25 de julio 2021: "de cara al Bicentenario y las elecciones soberanas de Nicaragua este 7 de noviembre, debemos avanzar, hasta hacer realidad nuestra segunda y definitiva independencia".

\section{¡LA REVOLUCION SANDINISTA, EN BUSCA DE LA SEGUNDA INDEPENDENCIA!}

\section{Bibliografia}

Barricada (1980), Organo Oficial del FSLN. Domingo 2 de marzo. Managua, Nicaragua. Año II.N.421.Managua,Nicaragua.

Barricada (1980). Organo Oficial del FSLN. Jueves 2 de octubre.Año II.N.421.Managua,Nicaragua.

Barricada (1980), Organo Oficial del FSLN. Testimonio de Yma Yara y Reyna Arroliga alfabetizadoras de Nueva Guinea. Viernes 7 de marzo. Managua, Nicaragua.

Hobsbawm, Eric, J (1983), Rebeldes primitivos, Estudio sobre las formas arcaicas de los movimientos sociales en los siglos XIX y XX, editorial Ariel, S.A. Barcelona.

Kinloch Tijerino, Francés (2008). Historia de Nicaragua.zera Edición. HNCA-UCA. Managua, Nicaragua.

Lobato Blanco, L.A. (2006). Auge de la Universidad y Desarrollo de la UNAN, Managua, desde la década de los ochenta los tiempos actuales. UNAN, Managua, Nicaragua. 


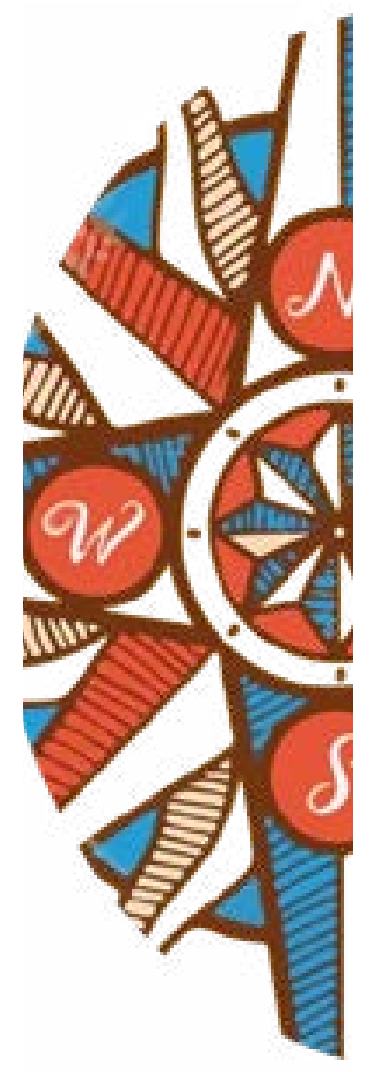

Orozco Alvarado, J. (2016). La didáctica de las Ciencias Sociales en la carrera Ciencias Sociales. Impacto, en el desempeño de los docentes del área de Ciencias Sociales de Managua. Tesis Doctoral. FAREM-Chontales: UNAN-Managua. Recuperado de: http://repositorio.unan.edu.ni/3824/1/60014.pdf

Ochoa Darling (2002), et - al, Monografía sobre El movimiento estudiantil como UNAN-Managua, diciembre del 2002, página 64.

Vilas, M. Carlos (1984), Perfiles de la revolución Sandinista , Editorial, Casa de las Américas, Habana, Cuba

Ramos Escobar Urías W (2008), La epopeya de la Cruzada Nacional de Alfabetización en 1980, UNAN, Managua, Nicaragua.

Ramos Escobar, U.W. (1979-1990). Memorias escritas de sobre la participación en los años ochenta en las movilizaciones a los frentes de guerra y la Prepa, Managua Nicaragua.

Ramos Escobar, U.W. y Ramos Araica J. (2016), La guerra contrarrevolucionaria en Nicaragua 1980-1990, Trabajo inédito, UNAN, Managua, Nicaragua.

Reyes Valles, N. (1979-1990). Memorias escritas de su participación en la década de los años 80, como guarda frontera en Nueva Segovia, Managua Nicaragua.

Traña Galeano, M (1990). Algunas notas sobre el movimiento estudiantil nicaragüense, en la primera mitad del SXIX. En Revista de Historia. Instituto de Historia de Nicaragua.

Urbina M. D. C (1980). Educación y lucha de clases en Nicaragua. Editorial Publicaciones del Departamento de Filosofía, UCA, Managua, Nicaragua.

Urbina M. D. C (2018). Summa Pedagógica. 1998-2018: Veinte años pensando y escribiendo sobre la Educación de los Nicaraguense. Grupo Editorial, Lea. Managua, Nicaragua.

Urbina M. D.C (2016). La rama del olivo. Una cultura de paz global. "Martín Luther King”. UPOLI. Managaua, Nicaragua.

Urbina M. D. C (2018). La Cruzada Nacional de Alfabetización nos salvó de la "muerte". Revista Correo de Nicaragua. Managua, Nicaragua.

Urbina M. D. C (1972). Educación para la modernización en Nicaragua. Primera Edición, Editorial PAIDOS. Buenos Aires Argentina.

Silva Rodríguez. J. F (1998). "Historia Regional y Local problemas: Teóricos Metodológicos. Primera Edición. Habana, Cuba. 
Docente-Investigador del Departamento de Historia de la UNAN-Managua, URACCAN-Nueva Guinea. Técnico Superior en Historia, Licenciado en Historia. Maestro en Estudios Latinoamericano y del Caribe, con una especialización en Educación, Madrid, España. Autor y coautor de varios libros sobre Historia Local y Regional, articulistas de varias Revistas y Diarios nacionales, subdirector de un centro educativo y metodólogo de la Escuela Preparatoria de la UNAN-Managua.

\section{Herme J. Ramos Araica}

Titular del INC ( Instituto Nacional de Cultura), en el Área de Arqueología, Licenciado en Historia con mención en Arqueología. Docente de la UPOLI, participante en al análisis de Material Cerámico y Lítico del Proyecto del Gran Canal Interoceánico de Nicaragua dirigido por el Dr. Manuel Román Lacayo en el 2014.

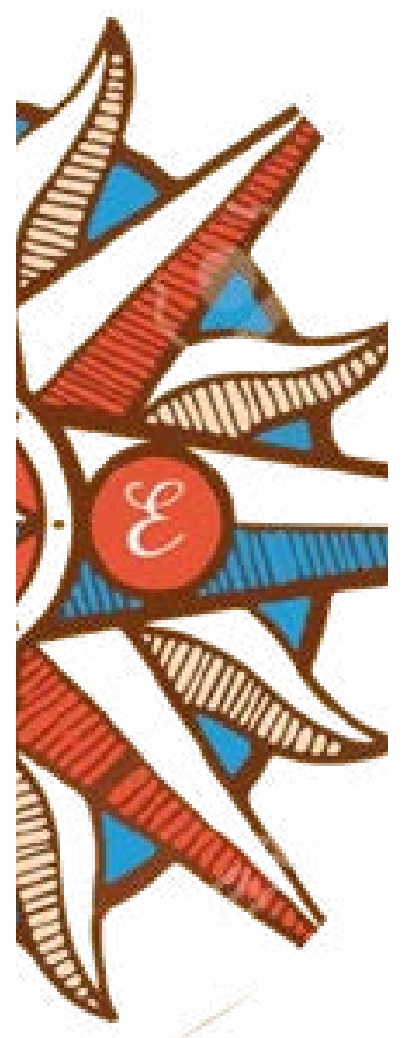

